\title{
Production of Microbial Bio-Pesticides from Waste Disposal of Chicken Feathers
}

\author{
Poopathi $\mathbf{S}^{1 *}$, Murugan $\mathrm{K}^{2}$, Selvakumari $\mathbf{J}^{1}$, Mani $\mathbf{C}^{1}$, Bala $\mathbf{P}^{1}$, de Britto RLJ ${ }^{1}$, Pattnaik $\mathbf{S}^{3}$, Santhosh Goud ${ }^{3}$ and Prabakaran $\mathbf{K}^{4}$ \\ ${ }^{1}$ Vector Control Research Centre (Indian Council of Medical Research), Indira Nagar, Puducherry, India \\ ${ }^{2}$ Vice-Chancellor, Thiruvalluvar University, Serkkadu, Vellore, Tamil Nadu, India \\ ${ }^{3}$ Post-graduate Department of Zoology, Berhampur University, Berhampur, Odisha, India \\ ${ }^{4}$ Department of Zoology, Kanchi Mamunivar Centre for Postgraduate Studies (Autonomous), Lawspet, Puducherry, India
}

*Corresponding author: Poopathi S, Vector Control Research Centre (Indian Council of Medical Research), Indira Nagar, Puducherry, India, Tel: 0413 227 2396; Email: Subbiahpoopathi@rediffmail.com

Received date: August 18, 2016; Accepted date: August 26, 2016; Published date: August 31, 2016

Copyright: @ 2016 Poopathi S, et al. This is an open-access article distributed under the terms of the Creative Commons Attribution License, which permits unrestricted use, distribution, and reproduction in any medium, provided the original author and source are credited.

\section{Editorial}

Chicken feathers, obtainable worldwide, as a cheap bioorganic waste, are an extremely valuable substrates, for the commercial production of bio-pesticide by entomopathogenic bacteria (Bacillus thuringiensis serovar israelensis, Bti and B. sphaericus, Bs), mainly in emerging nations, in the direction of vector control operation. Every day, huge amount of bio-organic wastes are released from food based manufacturing industries, poultries, factories and fisheries. Alternative disposal or bio-remediation methods are investigated for disposal of different wastes like sludge, various liquid wastes, organic and solid wastes discharged from food processing industries. Discarding or handling of these kinds of wastes as untreated disposal without gaining additional profit has led to develop the bio-pesticides by using bioorganic waste substances into cost-effective vector control programs.

Chicken feathers were characterized for their chemical composition and generally it accumulated proteins, mainly keratins. Keratins are the major structural proteins which are highly resistant against biodegradation [1]. Earlier researchers reported that B. licheniformis can utilized to degrade keratin containing waste from poultry forms by producing keratin degrading enzyme (keratinase) for making animal feed and manure [2-4]. Keratins are made up two main subunits such as alpha and beta keratins which composed various amino acids [5]. The feathers are mainly composed of beta-keratin [6,7]. The investigation spotlights on degradation of the keratin containing chicken feathers by the bacterial strains of $B$. thuringiensis serovar israelensis (Bti) and Bacillus sphaericus (Bs) which are helpful in the production of endotoxins to destroy the mosquito larvae.

B. thuringiensis serovar israelensis (Bti) and B. sphaericus (Bs) has been gaining much importance, in mosquito larval control programs, as a proficient substitute to conventional insecticides. The mosquito larvicidal property of Bs and Bti is mainly due to the existence of intracellular crystal toxins, synthesized during sporulation (Bs: 51 and $42 \mathrm{kDa}$ proteins; Bti: 134, 125, 67 and $27 \mathrm{kDa}$ proteins) [8,9]. Nevertheless, the cost of producing these bacteria, utilizing conventional culture media (like LB, NB, NYSM, etc.), is very high. As a result, selection of other efficient, but, cost-effective substrates have alternative to, by many researchers $[10,11]$. The purpose of this editorial review is to investigate the feasibility of degrading keratin containing waste, disposed in mass as environmental waste, for the making of culture media to fabricate bacterial toxins (Bti and Bs). This technique helps to maintain a cleaner environment by avoiding the dumping of poultry waste.
All forms of chicken feather waste (CFW) such as, filoplume, semiplume and contour from broiler chickens (Gallus gallus) were gathered from the poultry industries, rinsed with distilled water, airdried, powdered to fine powder reliability in a grinding mill and stored in packed condition at room temperatures. Five gram of chicken feather powder was mixed with one litre of tap water and the $\mathrm{pH}$ was adjusted. This feather medium was distributed in three conical flasks for culturing Bti, Bs and control medium (medium without inoculation of bacteria) respectively. Similar flasks were also kept for conventional culture medium. After autoclaving a small quantity Bs and Bti was inoculated and allowed to grow for 72 hours. After complete sporulation, spores/crystals were harvested and lyophilized for bioassays. The result showed that the bacteria (Bs and Bti) grown under CFW-culture medium degraded the feathers by consuming the keratins and ultimately the bacteria synthesized the crystal toxins.

It is known that every day, large quantity of feathers waste is discarded, by poultry producing industries as a waste byproduct and as well as an ecological hazard. Many methods have been implemented to dispose this bulk feather waste, which include land filling, burning, production of natural gas and fertilizer [12-14]. The basic idea of the study was to utilize the entire chicken feather waste (CFW), as a costeffect substrate, for bio-pesticide production. The emphasizing principle was based on the complete bio-degradation of structural proteins (keratin) of feathers from the chicken by the bacterial strains (Bti and Bs). Characterization of feather waste exposes that the chemical composition consists of protein (81\%), fat (1.2\%) ash (1.3\% and dry matter. As it is a balanced medium it does not require other nutrients for culturing the degrading bacteria. This fermentation technology assists the complete utilization of CFW, by avoiding any kind of resultant residual loss or wastage, resulting in an improved production of bio-pesticides and retaining a cleaner environment. This study is, of much relevance, as it supports the dual benefits of complete consumption of chicken feather waste from the environment and as well as the production of bio-pesticides.

The growth pattern of bacterial cells, a displaying of biomass production was predicted by different time interval. This was measured by OD values of the bacterial samples (at $650 \mathrm{~nm}$ ). In both CFW and NYSM, after a lag phase, there was a rapid growth of bacterial cells and spore maturation till 48 hours. The density of bacterial culture showed a corresponding enhance and attained a plateau (range 2t o 2.5). This was continuous by cell lysis, discharging the endotoxins into the medium, attaining a peak at 72 hours. Thus, the growth and production of Bti and Bs from CFW, was comparable, to that of NYSM and the mean values were not considerably diverse $(P>0.05)$. The microscopic observation of $\mathrm{Bs}$ and $\mathrm{Bti}$ spores/crystal complex, 
acquired from CFW and NYSM, after 72 hours growth, specified that, the sporulation in the latter medium was as better from previous one. The major polypeptides of Bti and Bs spore/crystal complex fashioned from NYSM and CFW (Bti: 134, 125, 67 and $27 \mathrm{kDa}$ and Bs: 51 and 42 $\mathrm{kDa}$ proteins) was conspicuous. There was no difference in the protein pattern, between the toxins, fashioned from these two different culture media.

The comparative toxicity analysis of Bti and Bs toxins fashioned from CFW and NYSM were satisfactory. The LC50 and LC90 values over Cx. quinquefasciatus for Bti (NYSM) were 0.0067 and $0.01 \mathrm{mg} / \mathrm{l}$ correspondingly and for Bti (CFW) were 0.007 and $0.01 \mathrm{mg} / \mathrm{l}$ correspondingly, which were statistically parallel (fiducial limits overlapping). The other two (Anopheles stephensi and Aedes aegypti) mosquito species, also revealed similar toxicity effects. The Bs toxins fashioned from CFW, in association with that of NYSM was also examined. The Bs produced from CFW was more active against major mosquito species tested and was accounted to be equally comparable to the toxins fashioned from previous (NYSM). It is worth stating here that, the Bti toxins produced from both the culture media showed a high lethal effect on the larvae than the Bs toxins, clearly, due to the existence of compound toxins in Bti (Figure 1).

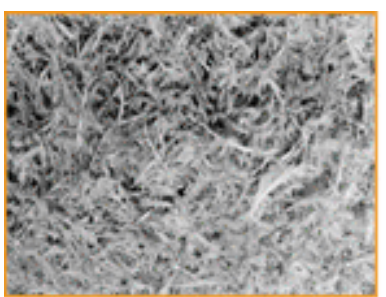

Feather waste

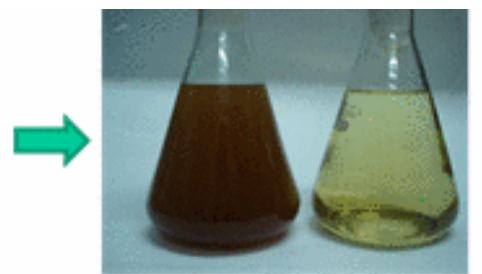

Media: CFW \& NYSM

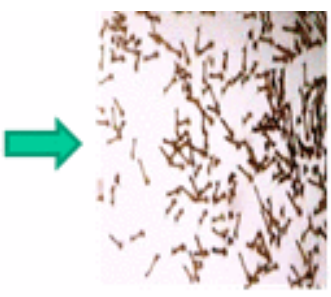

Dead mosquito larvae

Figure 1: Biopesticide production from chicken feather waste (CFW)

Cost-effective analysis showed that the amount of feather waste powder necessary to prepare one liter of CFW was only $0.5 \%$ (5 g CFW in 1 liter water), which is cost free, being a poultry waste. On the different, preparation of one liter of NYSM involved a price of US \$ 3.6. This shows that CFW was cheaper than NYSM, nevertheless, the bacterial growth, toxin production and toxicity levels of test (CFW) and conventional (NYSM) media was similar. These results permit us to conclude that, the use of CFW, in the dried powder form $(0.5 \%)$, had manifold benefits, like whole degradation of chicken feather waste, to avoid environmental contamination, improved shelf-life, easy maintenance, shipping and feasibility in handling and application. This technique is extremely cheap; as it needs relatively a small amount of raw material (feathers) for culture media preparation to grow the bacteria which proving high efficiency of bacterial growth and toxicity, over vector mosquitoes.

\section{References:}

1. Ramnani P, Singh R, Gupta R (2005) Keratinolytic potential of Bacillus licheniformis RG1: structural and biochemical mechanism of feather degradation. Can J Microbiol 51: 191-196.

2. Riffel A, Brandelli A (2002) Isolation and characterization of a feather degrading bacterium from the poultry processing industry. J Ind Microbiol Biotechnol 29: 255-258.

3. Ramnani P, Gupta R (2004) Optimization of medium composition for keratinase production on feather by Bacillus licheniformis RG1 using statistical methods involving response surface methodology. Biotechnol Appl Biochem 40: 191-196.

4. Wang JJ, Greenhut WB, Shih JC (2005) Development of an asporogenic Bacillus licheniformis for the production of keratinase. J Appl Microbiol 98: 761-767.
5. Kim WK, Lorenz ES, Patterson PH (2002) Effect of enzymatic and chemical treatments on feather solubility and digestibility. Poult Sci 81: 95-98.

6. Takahashi K, Yamamoto H, Yokote Y, Hattori M (2004) Thermal behavior of fowl feather keratin. Biosci Biotechnol Biochem 68: 875- 881.

7. Gupta R, Ramnani P (2006) Microbial keratinases and their prospective applications: an overview. Appl Microbiol Biotechnol 70: 21-33.

8. Poopathi S, Anupkumar K, Kabilan L, Sekar V (2002) Development of lowcost media for the culture of mosquito larvicides, Bacillus sphaericus and Bacillus thuringiensis serovar israelensis. World Journal of Microbiology and Biotechnology 18: 209-216.

9. Poopathi S, Anup Kumar K (2004) Novel fermentation medium for the production of Bacillus thuringiensis serovar israelensis, in mosquito control. J Econ Entomol 96: 1039- 1044.

10. Ventosilla P, Guerra H (1997) Pilot production using whole coconuts and application in the field of Bacillus thuringiensis var. israelensis for biological control of Anopheles in malaria endemic areas in Peru. Revista de Medicina Experimental del Instituto Nacional de Salud. Segunda Epoca 16: 61.

11. Boothe DD, Arnold JW, (2002) Nutrient substrates used by bacterial isolates from the poultry processing environment. Poult Sci 81: 1392-1405.

12. Balint B, Bagi Z, Toth A, Rakhely G, Perei K, et al. (2005) Utilization of keratin containing biowaste to produce biohydrogen. Appl Microbiol Biotechnol 69: 404-410.

13. Bertsch A, Coello N (2005) A biotechnological process for treatment and recycling poultry feathers as a feed ingredient. Bioresource Technology 96: 1703-1708.

14. Zerdani I, Faid M, Malki A (2004) Feather wastes digestion by new isolated strains Bacillus sp. In Morocco. Afri J Biotechnol 3: 67-70. 